\title{
Evaluation of the Order SMARTT: An Initiative to Reduce Phlebotomy and Improve Sleep-Friendly Labs on General Medicine Services
}

\author{
Natalie Tapaskar, MD1*, Megha Kilaru, MPH², Tipu S Puri, MD, PhD'1, Shannon K Martin, MD, MS1,

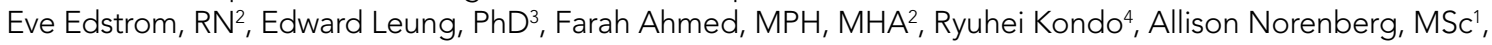 \\ Elizabeth Poli, MD5, Vineet M Arora, MD, MAPP'
}

\begin{abstract}
${ }^{1}$ Department of Medicine, University of Chicago, Chicago, Illinois; ${ }^{2}$ Center for Healthcare Delivery Science and Innovation, University of Chicago Medicine, Chicago, Illinois; ' 2 epartment of Pathology and Laboratory Medicine, Children's Hospital of Los Angeles, Los Angeles, California; ${ }^{4}$ Booth School of Business, University of Chicago, Chicago, Illinois; ${ }^{5}$ Department of Surgery, University of Chicago, Chicago, Illinois.
\end{abstract}

We assessed the effectiveness of a quality improvement project to reduce routine labs in clinically stable patients, while also promoting sleep-friendly lab timing. The electronic health record was modified with an "Order Sleep" shortcut to facilitate sleep-friendly lab draws. A "4 AM Labs" column was added to electronic patient lists to signal which patients had early morning labs ordered. Among 7,045 patients over 50,951 total patient-days, on average we observed $26.3 \%$ fewer routine lab draws per patient-day per week postintervention (4.68 before vs 3.45 after; difference, 1.23; $95 \% \mathrm{Cl}, 0.82-1.63 ; P<.05)$. In interrupted time series analysis, the "Order Sleep" tool was associated with a significant increase in sleep-friendly lab orders per encounter per week on resident medicine services (intercept, 1.03; standard error (SE), 0.29; $P<.001)$. The "4 AM Labs" column was associated with a significant increase in sleep-friendly lab orders per patient encounter per week on the hospitalist medical service (intercept, 1.17; SE, 0.50; $P=.02$ ). We demonstrate the success of an initiative to simultaneously reduce daily labs and improve sleep-friendly ordering. Journal of Hospital Medicine 2020;15:479-482. (C) 2020 Society of Hospital Medicine

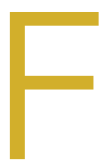

requent daily laboratory testing for inpatients contributes to excessive costs, ${ }^{1}$ anemia, ${ }^{2}$ and unnecessary testing. $^{3}$ The ABIM Foundation's Choosing Wisely ${ }^{\circledR}$ campaign recommends avoiding routine labs, like complete blood counts (CBCs) and basic metabolic panels (BMP), in the face of clinical and laboratory stability. ${ }^{4,5}$ Prior interventions have reduced unnecessary labs without adverse outcomes. . $^{6.8}$

In addition to lab frequency, hospitalized patients face suboptimal lab timing. Labs are often ordered as early as 4 AM at many institutions. ${ }^{9,10}$ This practice disrupts sleep, undermining patient health. ${ }^{11-13}$ While prior interventions have reduced daily phlebotomy, few have optimized lab timing for patient sleep..$^{10}$ No study has harnessed the electronic health record (EHR) to optimize frequency and timing of labs simultaneously. ${ }^{14} \mathrm{We}$ aimed to determine the effectiveness of a multicomponent intervention, called Order SMARTT (Sleep: Making Appropriate Reductions in Testing and Timing), to reduce frequency and optimize timing of daily routine labs for medical inpatients.

\footnotetext{
*Corresponding Author: Natalie Tapaskar, MD; Email: Natalie.tapaskar@gmail. com; Telephone: 630-303-6574; Twitter: @NatalieTapaskar.

Published online first July 22, 2020.

Find additional supporting information in the online version of this article.
}

Received: December 21, 2019; Revised: March 11, 2020;

Accepted: March 28, 2020

๑) 2020 Society of Hospital Medicine DOI 10.12788/jhm.3423

\section{METHODS}

\section{Setting}

This study was conducted on the University of Chicago Medicine (UCM) general medicine services, which consisted of a resident-covered service supervised by general medicine, subspecialist, or hospitalist attendings and a hospitalist service staffed by hospitalists and advanced practice providers.

\section{Development of Order SMARTT}

To inform intervention development, we surveyed providers about lab-ordering preferences with use of questions from a prior survey to provide a benchmark (Appendix Table 2). ${ }^{15}$ While reducing lab frequency was supported, the modal response for how frequently a stable patient should receive routine labs was every 48 hours (Appendix Table 2). Therefore, we hypothesized that labs ordered every 48 hours may be popular. Taking labs every 48 hours would not require an urgent 4 AM draw, so we created a 48-hour 6 AM phlebotomy option to "step down" from daily labs. To promote these options, we created two EHR tools: First, an "Order Sleep" shortcut was launched in March 2018 by which physicians could type "sleep" in routine lab orders and three sleep-friendly options would become available (a 48-hour 6 AM draw, a daily 6 AM draw, or a daily 10 PM draw), and second, a "4 AM Labs" column and icon on the electronic patient list to signal who had 4 AM labs ordered was launched May 2018 (Appendix Table 1).

\section{Physician Education}

We created a 20-minute presentation on the harms of excessive labs and the benefits of sleep-friendly ordering. Instructional 
TABLE. Summary of Sleep-Friendly Lab Orders*

\begin{tabular}{|c|c|c|c|}
\hline Intervention & All General Medicine & Resident General Medicine Service & Hospitalist General Medicine Service \\
\hline \multicolumn{4}{|l|}{ Order Sleep } \\
\hline Immediately After Launch ${ }^{\mathrm{a}}$ & $0.49(\mathrm{SE}, 0.14 ; P=.001)$ & $1.03(\mathrm{SE}, 0.29 ; P<.001)$ & $-2.77(\mathrm{SE}, 1.44, P=.06)$ \\
\hline \multicolumn{4}{|l|}{4 Am Labs Column } \\
\hline Immediately After Launch ${ }^{\mathrm{a}}$ & $0.32(\mathrm{SE}, 0.13 ; P=.02)$ & $-0.08(\mathrm{SE}, 0.17 ; P=.62)$ & $1.17(\mathrm{SE}, 0.50 ; P=.02)$ \\
\hline \multicolumn{4}{|c|}{$\begin{array}{l}\text { "A summary of the rates at which lab orders per patient encounter per week changed relative to the two interventions; } P<.05 \text { was considered significant, and negative rates indicate a decrea } \\
\text { in rates of sleep-friendly lab ordering. }\end{array}$} \\
\hline \multicolumn{4}{|c|}{ aResults immediately after launch of the intervention are presented as an intercept change in the rate. } \\
\hline \multicolumn{4}{|c|}{ bResults during the time after launch are presented as a change in slope. } \\
\hline Abbreviation: $\mathrm{SE}$, standard error. & & & \\
\hline
\end{tabular}

Order SMARTT posters were posted in clinician workrooms that emphasized forgoing labs on stable patients and using the "Order Sleep" shortcut when nonurgent labs were needed.

\section{Labs Utilization Data}

We used Epic Systems software (Verona, Wisconsin) and our institutional Tableau scorecard to obtain data on CBC and BMP ordering, patient census, and demographics for medical inpatients between July 1, 2017, and November 1, 2018.

\section{Cost Analysis}

Costs of lab tests (actual cost to our institution) were obtained from our institutional phlebotomy services' estimates of direct variable labor and benefits costs and direct variable supplies cost.

\section{Statistical Analysis}

Data analysis was performed with SAS version 9.4 statistical software (Cary, North Carolina, USA) and R version 3.6.2 (Vienna, Austria). Descriptive statistics were used to summarize data. Surveys were analyzed using chi-square tests for categorical variables and two-sample $t$ tests for continuous variables. For lab ordering data, interrupted time series analyses (ITSA) were used to determine the changes in ordering practices with the implementation of the two interventions controlling for service lines (resident vs hospitalist service). ITSA enables examination of changes in lab ordering while controlling for time. The AUTOREG function in SAS was used to build the model and estimate final parameters. This function automatically tests for autocorrelation, heteroscedasticity, and estimates any autoregressive parameters required in the model. Our main model tested the association between our two separate interventions on ordering practices, controlling for service (hospitalist or resident). ${ }^{16}$

\section{RESULTS}

Of 125 residents, 82 (65.6\%) attended the session and completed the survey. Attendance and response rate for hospitalists was $80 \%$ ( 16 of 20 ). Similar to a prior study, many residents (73.1\%) reported they would be comfortable if patients re- ceived less daily laboratory testing (Appendix Table 2).

We reviewed data from 7,045 total patients over 50,951 total patient days between July1, 2017, and November 1, 2018 (Appendix Table 3).

\section{Total Lab Draws}

After accounting for total patient days, we saw $26.3 \%$ reduction on average in total lab draws per patient-day per week postintervention (4.68 before vs 3.45 after; difference, 1.23; $95 \% \mathrm{Cl}, 0.82-1.63 ; P<.05 ;$ Appendix Table 3). When total lab draws were stratified by service, we saw $28 \%$ reduction on average in total lab draws per patient-day per week on resident services (4.67 before vs 3.36 after; difference, 1.31; $95 \%$ $\mathrm{Cl}, 0.88-1.74 ; \mathrm{P}<.05)$ and $23.9 \%$ reduction on average in lab draws/patient-day per week on the hospitalist service (4.73 before vs 3.60 after; difference, 1.13; $95 \% \mathrm{Cl}, 0.61-1.64 ; P<.05$; Appendix Table 3).

\section{Sleep-Friendly Labs by Intervention}

For patients with routine labs, the proportion of sleep-friendly labs drawn per patient-day increased from $6 \%$ preintervention to $21 \%$ postintervention $(P<.001)$. ITSA demonstrated both interventions were associated with improving lab timing. There was a statistically significant increase in sleep-friendly labs ordered per patient encounter per week immediately after the launch of "Order Sleep" (intercept, 0.49; standard error (SE), $0.14 ; P=.001$ ) and the "4 AM Labs" column (intercept, 0.32; SE, $0.13 ; P=.02 ;$ Table, Figure A).

\section{Sleep-Friendly Lab Orders by Service}

Over the study period, there was no significant difference in total sleep-friendly labs ordered/month between resident and hospitalist services (84.88 vs $86.19 ; P=.95)$.

In ITSA, "Order Sleep" was associated with a statistically significant immediate increase in sleep-friendly lab orders per patient encounter per week on resident services (intercept, 1.03; SE, 0.29; $P<.001$ ). However, this initial increase was followed by a decrease over time in sleep-friendly lab orders per week (slope change, $-0.1 ; \mathrm{SE}, 0.04 ; P=.02$; Table, Figure B). There was no statistically significant change 

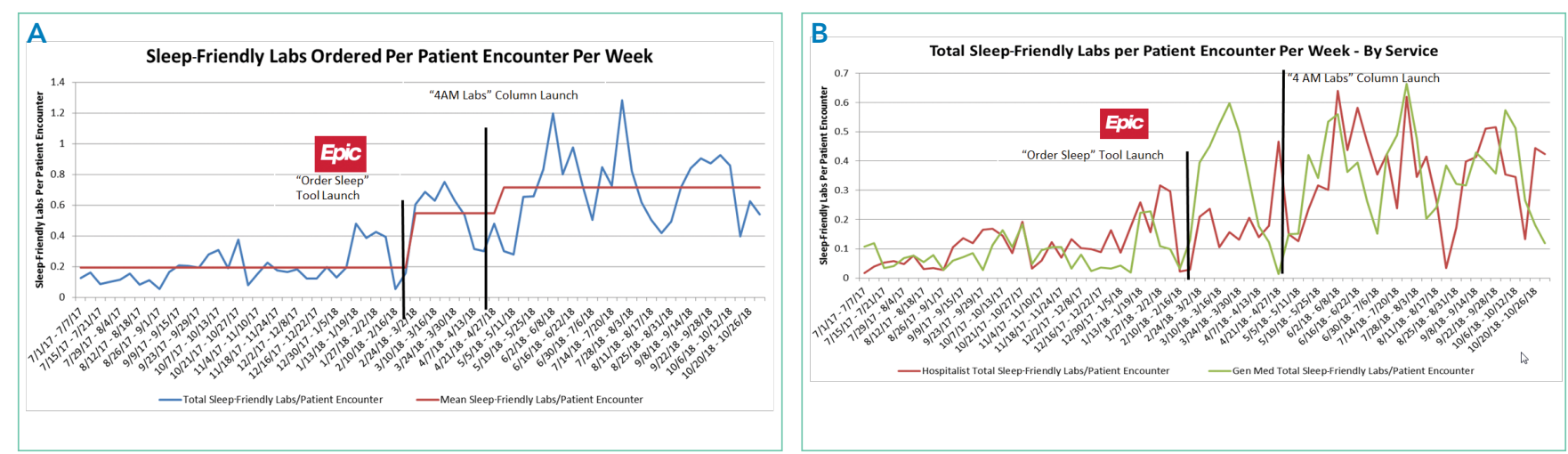

FIG. (A) Run chart of sleep-friendly lab orders per unique patient encounter per week. First vertical line indicates the launch of the "Order Sleep" Tool intervention and the second represents the launch of the "4 AM Labs" Column. The red line indicates the mean sleep-friendly labs ordered per patient encounter. There is a significant increase in sleep-friendly lab orders after both interventions. (B) Run chart of sleep-friendly labs per unique patient encounter per week by service type. The green line represents resident general medicine services and the red is hospitalist. First vertical line indicates the launch of the "Order Sleep" Tool intervention and the second represents the launch of the " 4 AM Labs" Column. Prior to the interventions, there was no significant difference in sleep-friendly lab ordering between the two services. On resident general medicine services there is a significant increase in sleep-friendly lab ordering after the "Order Sleep" Tool launch, which is followed by a significant decrease until the launch of the "4 AM Labs" column. On hospitalist services, there was a significant increase in sleep-friendly lab ordering after launch of the "4 Am Labs" Column.

observed on the hospitalist service with "Order Sleep."

In contrast, the "4 AM Labs" column was associated with a statistically significant immediate increase in sleep-friendly lab orders per patient encounter per week on hospitalist service (intercept, 1.17; SE, 0.50; $P=.02$; Table, Figure B). While there was no immediate change on resident service, we observed a significant increase over time in sleep-friendly orders per encounter per week on resident services with the introduction of the "4 AM Labs" column (slope change, 0.11; SE, 0.04; $P=.01$; Table, Figure B).

\section{Cost Savings}

Using an estimated cost of $\$ 7.70$ for CBCs and $\$ 8.01$ for BMPs from our laboratory, our intervention saved an estimated $\$ 60,278$ in lab costs alone over the 16-month study period (Appendix Table 4).

\section{DISCUSSION}

To our knowledge, this is the first study showing a multicomponent intervention using EHR tools can both reduce frequency and optimize timing of routine lab ordering. Our project had two interventions implemented at two different times: First, an "Order Sleep" shortcut was introduced to select sleep-friendly lab timing, including a 6 AM draw every 48 hours, and later, a "4 AM Labs" column was added to electronic patient lists to passively nudge physicians to consider sleep-friendly labs. The "Order Sleep" tool was associated with a significant immediate increase in sleep-friendly lab ordering on resident services, while the "4 AM Labs" column was associated with a significant immediate increase in sleep-friendly lab ordering on the hospitalist service. An overall reduction in total lab draws was seen on both services.

While the "Order Sleep" tool was initially associated with significant increases in sleep-friendly orders on resident services, this change was not sustained. This could have been caused by the short-lived effect of education more than sustained adoption of the tool. In contrast, the "4 Am Labs" column on the patient list resulted in a significant sustained increase in sleep-friendly labs on resident services. While residents responded to both tools, both interventions were associated with lasting changes in practice.

The "4 Am Labs" column on patient lists was associated with increased adoption of sleep-friendly labs for hospitalist services. Hospitalists care for a larger census with more frequent handoffs and greater reliance on the patient list, which makes patient lists in general an important tool to target value improvement.

While other institutions have attempted to shift lab-timing by altering phlebotomy workflows ${ }^{10}$ or via conscious decision-making on rounds, ${ }^{9}$ our study differs in several ways. We avoided default options and allowed clinicians to select sleep-friendly labs to promote buy-in. It is sometimes necessary to order 4 Am labs for sick patients who need urgent decision-making, which highlights the need to preserve this option for clinicians. Similarly, our intervention did not aim to eliminate lab draws entirely but offer a more judicious frequency of every 48 hours, consistent with the survey preferences noted. This intervention encouraged reappraisal of patients' overall needs for labs and created variability in ordering times to reduce the volume of labs ordered at 4 AM.

Our study had several limitations. First, this was a single center study on adult medicine services, which limits generalizability. Although we considered surgical services, their early rounds made deviations from 4 AM undesirable. Given the observational study design, we cannot assume causal relationships or rule out secular trends. There were large swings in sleep-friendly lab ordering during our study that could be attributed to different physicians rotating on the services monthly. We did not obtain objective data on patient sleep or patient satisfaction because of the low response rate to the HCAHPS (Hospital Consumer Assessment of Healthcare Providers and Systems) survey. 
In conclusion, a multicomponent intervention using EHR tools can reduce inpatient daily lab frequency and optimize lab timing to help promote patient sleep.

\section{Acknowledgments}

The authors would like to thank The University of Chicago Center for Healthcare Delivery Science and Innovation for sponsoring their annual Choosing Wisely Challenge, which allowed for access to institutional support and resources for this study. We would also like to thank Mary Kate Springman, MHA, and John Fahrenbach, PhD, for their assistance with this project. Dr Tapaskar also received mentorship through the Future Leader Program for the High Value Practice Academic Alliance.

Disclosures: The authors have no financial disclosures.

Funding: This research was supported by NHLBI K24 HL136859 and the Center for Healthcare Delivery Sciences and Innovation Choosing Wisely ${ }^{\circledast}$ Challenge at University of Chicago Medicine.

\section{References}

1. Eaton KP, Levy K, Soong C, et al. Evidence-based guidelines to eliminate repetitive laboratory testing. JAMA Intern Med. 2017;177(12):1833-1839. https://doi.org/10.1001/jamainternmed.2017.5152

2. Thavendiranathan P, Bagai A, Ebidia A, Detsky AS, Choudhry NK. Do blood tests cause anemia in hospitalized patients? J Gen Intern Med. 2005;20(6):520-524. https://doi.org/10.1111/j.1525-1497.2005.0094.x

3. Korenstein D, Husain S, Gennarelli RL, White C, Masciale JN, Roman BR. Impact of clinical specialty on attitudes regarding overuse of inpatient laboratory testing. J Hosp Med. 2018;13(12):844-847. https://doi.org/10.12788 /jhm.2978

4. Choosing Wisely. 2020. Accessed January 10, 2020. http://www.choosingwisely.org/getting-started/

5. Bulger J, Nickel W, Messler J, et al. Choosing wisely in adult hospital medicine: five opportunities for improved healthcare value. J Hosp Med.
2013;8(9):486-492. https://doi.org/10.1002/jhm.2063

6. Stuebing EA, Miner TJ. Surgical vampires and rising health care expenditure: reducing the cost of daily phlebotomy. Arch Surg. 2011;146(5):524-527. https://doi.org/10.1001/archsurg.2011.103

7. Attali M, Barel $Y$, Somin M, et al. A cost-effective method for reducing the volume of laboratory tests in a university-associated teaching hospital. Mt Sinai J Med. 2006;73(5):787-794.

8. Vidyarthi AR, Hamill T, Green AL, Rosenbluth G, Baron RB. Changing resident test ordering behavior: a multilevel intervention to decrease laboratory utilization at an academic medical center. Am J Med Qual. 2015;30(1):81-87. https://doi.org/10.1177/1062860613517502

9. Krafft CA, Biondi EA, Leonard MS, et al. Ending the 4 AM Blood Draw. Presented at: American Academy of Pediatrics Experience; October 25, 2015, Washington, DC. Accessed January 10, 2020. https://aap.confex.com/ aap/2015/webprogrampress/Paper31640.html

10. Ramarajan V, Chima HS, Young L. Implementation of later morning specimen draws to improve patient health and satisfaction. Lab Med. 2016;47(1):e1-e4. https://doi.org/10.1093/labmed//mv013

11. Delaney LJ, Van Haren F, Lopez V. Sleeping on a problem: the impact of sleep disturbance on intensive care patients - a clinical review. Ann Intensive Care. 2015;5:3. https://doi.org/10.1186/s13613-015-0043-2

12. Knutson KL, Spiegel K, Penev P, Van Cauter E. The metabolic consequences of sleep deprivation. Sleep Med Rev. 2007;11(3):163-178. https://doi.org/10.1016/j.smrv.2007.01.002

13. Ho A, Raja B, Waldhorn R, Baez V, Mohammed I. New onset of insomnia in hospitalized patients in general medical wards: incidence, causes, and resolution rate. J Community Hosp Int. 2017;7(5):309-313. https://doi.org/10.108 0/20009666.2017.1374108

14. Arora VM, Machado N, Anderson SL, et al. Effectiveness of SIESTA on objective and subjective metrics of nighttime hospital sleep disruptors. $J$ Hosp Med. 2019;14(1):38-41. https://doi.org/10.12788/jhm.3091

15. Roman BR, Yang A, Masciale J, Korenstein D. Association of Attitudes Regarding Overuse of Inpatient Laboratory Testing With Health Care Provider Type. JAMA Intern Med. 2017;177(8):1205-1207. https://doi.org/10.1001/jamainternmed.2017.1634

16. Penfold RB, Zhang F. Use of interrupted time series analysis in evaluating health care quality improvements. Acad Pediatr. 2013;13(6 Suppl):S38-S44. https://doi.org/10.1016/j.acap.2013.08.002 